\title{
Carbon Sequestration in Soils for Different Land Use Systems: A Review
}

\author{
Mukesh Gupta ${ }^{1}$, D. K. Vani ${ }^{2}$ and Sourav Gupta ${ }^{3 *}$ \\ ${ }^{1}$ Department of Agricultural Economics, ${ }^{2}$ Department of Agricultural Engineering, \\ ${ }^{3}$ Department of Agronomy, RA (DAMU), Krishi Vigyan Kendra, Khandwa, M.P., India \\ *Corresponding author
}

\section{A B S T R A C T}

\begin{tabular}{|c|}
\hline Keywords \\
\hline $\begin{array}{l}\text { Carbon } \\
\text { dynamics, } \\
\text { Carbon } \\
\text { sequestration, } \\
\text { GHG, } \\
\text { SOC }\end{array}$ \\
\hline Article Info \\
\hline $\begin{array}{l}\text { Accepted: } \\
04 \text { October } 2020 \\
\text { Available Online: } \\
10 \text { November } 2020\end{array}$ \\
\hline
\end{tabular}

Keywords

Carbon

dynamics,

Carbon

sequestration,

GHG
Developing land management scenarios that have the potential to sequester carbon and reduce greenhouse gasses (GHG) emission on a sustainable basis entails quantifying the current carbon stock under different land uses. Global climatic conditions due to human activities have directed towards utilizing soils as a resources to both mitigate and adapt to climate change. Soil organic carbon (SOC) has long been identified as a factor that is important to soil fertility as well as to the environment because of huge carbon sequestration potential of soils. The amount of carbon stored in soil organic matter is one of the largest and most dynamic reservoirs of carbon in the global cycle. Soil organic carbon (SOC) is the largest terrestrial pool of sequestered carbon (C) and therefore plays a pivotal role in global $\mathrm{C}$ dynamics. SOC is not just an inert $\mathrm{C}$ store, as it also influences the physical, chemical and biological properties of the soil, which have significant impact on sustainability of agriculture. SOC is therefore an indicator of both soil quality and environment stability. As sequestration of atmospheric $\mathrm{CO}_{2}$ in soils is an option to reduce global warming.

\section{Introduction}

Carbon sequestration is fixing atmospheric $\mathrm{CO}_{2}$ by physical, chemical or biological processes into long-lived carbon pools; such as ocean, soil, vegetation and geologic formation in a manner that it is not re-emitted into the atmosphere in the near future. Soils play a key role in maintaining a balanced global carbon cycle. Depending on the processes and technological innovations, there are three main types of carbon sequestration those based on the natural process of photosynthesis and conversion of atmospheric $\mathrm{CO}_{2}$ into biomass, soil organic matter or humus and other components of the terrestrial 
biosphere, those involving engineering techniques and those involving chemical transformations (Lal, 2008).

\section{Benefits of carbon sequestration}

Srinivasarao et al., (2012) reported several benefits of carbon sequestration:

Improvement in soil quality: Enhanced soil organic carbon content of soils results in improvement in the nutrient supplying capacity of the soil, improvement in soil physical properties and also enhanced microbial activity; which improves the crop growth favorably and provide better environment for crop growth.

Improved water holding capacity: Water holding capacity of soil is just that, the specific ability of a particular type of soil to hold water against the force of gravity.

The nature of the soil, composition of the soil, amount of organic component and size of the soil particles determine its ability to retain water. Soil organic matter compounds bind the primary particles in the aggregates, physically and chemically and this, in turn, increases the stability of the aggregates and water holding capacity of soil. Soil organic carbon builds up influence the water transmission properties of the soil viz.; hydraulic conductivity, infiltration and percolation through their influence on aggregation status, total porosity and the continuity of macro pores present in the soil.

Increasing crop productivity: Organic matter affects crop growth and yield, either directly by supplying nutrients, or indirectly by modifying soil physical properties that can improve the root environment and stimulate plant growth. It was estimated that each ton of profile organic carbon stock has potential to improve crop productivity up to $400 \mathrm{~kg} / \mathrm{ha} / \mathrm{yr}$.

\section{How is Carbon Sequestered in Soils?}

Since the size of the stable pool is generally static, soil carbon is effectively increased in the labile and slow pools by increasing the net balance of carbon that enters the soil every year relative to what is lost. Agricultural managers can strongly influence this dynamic in four ways:

Decreasing the level of soil disturbance (i.e. tillage) to enhance the physical protection of soil carbon in aggregates.

Increasing the mass and quality of plant and animal inputs to soils.

Improving soil microbial diversity and abundance.

Maintaining continuous living plant cover on soils year-round. Managing these processes can quickly lead to increases in soil carbon that may be highly useful in drawing down atmospheric $\mathrm{CO}_{2}$. The extent and permanence of soil-based carbon sequestration is currently under investigation and debate. Some of these contested issues are covered more completely in the following sections.

\section{Carbon sequestration in relation to soil fertility, land productivity and biodiversity}

Biodiversity, soil fertility and carbon sequestration are interlinked and should not be considered in isolation from one another. Above ground and underground biodiversity changes with land use changes over time. Soils contain more carbon than the world's biota. In developed countries soil carbon pool is in static equilibrium. The carbon stock in soils is either not changing or may be increasing. Great part of global carbon emission is coming from tropical agricultural deforestation area, where resource-poor farmers live on mining the soil nutrients and 
where most land degradation is occurring. Maximizing carbon sequestration in soils can probably best be done in so called set-aside lands. However the set-aside lands are only relevant in practice to industrialized countries, where there is a surplus of agricultural lands. In areas where the soil organic matter has been depleted, in part historically, the local farming community can receive government support, not just to leave the land uncultivated, but to use these set-aside lands to consciously increase soil organic matter content without any crops. The issue of maximization of carbon sequestration is less applicable to the developing countries where the combination of carbon sequestration with other purposes is much more relevant, although it may not produce the maximal storage of soil carbon.

A major element is improving soil productivity by increasing soil fertility and simultaneously facilitating carbon sequestration. FAO for the last 20 years has been promoting an integrated plant nutrition system (IPNS) approach in which the major emphasis is to optimize the benefits from all sources of plant nutrients (organic, biological and mineral) which implies a very essential linkage to carbon sequestration.

By applying organic fertilizers; soil organic carbon content can be enhanced resulting in increased biomass production. This biomass, when recycled, restores carbon into the soil. Land management practices, like conservation tillage and mulching, play a very important role in soil organic matter restoration.

\section{Role of land use and land management in carbon sequestration}

It was estimated that the $\mathrm{CO}_{2}$ concentration in the atmosphere is increasing at the rate of 3.3 thousand million ton a year. Therefore, stabilizing the $\mathrm{CO}_{2}$ concentration in the atmosphere is a very big objective which may not be achievable for a long time - hundreds of years, maybe millennia. What can be achieved, the experts argue, is to control emissions which have not been recognized very widely but which came from land management, land use and land cover change.

Estimates were given of about 50-100 thousand million tons from soils and another 100-150 thousand million tons from vegetation, giving a total of 150-250 thousand million tons. A considerable amount of emission, approximately 1.6 to 2.0 thousand million tons per year is attributed to deforestation, poor land management and land degradation by resource-poor farmers. This source of emission can be arrested by agricultural intensification on existing land, reducing deforestation and improving agricultural and forestry practices and by adopting conservation tillage. Carbon sequestration is, therefore, related to agricultural productivity, because it is also linked with poverty especially rural poverty. However the exact nature of the relationship is not yet clear, and in all likelihood it will not be the same in different environments and societies.

An achievable objective is to try to decrease $\mathrm{CO}_{2}$ emissions from land, especially on activities such as; deforestation, preventing land degradation, soil erosion control. It is necessary to narrow the problem down to decreasing emission from land and counter or reverse the effects of the emission process by sequestering carbon. That may be a doable objective. There should be less concern for carbon sequestration per second and more attention given to addressing the problem of carbon emission through land use. Two options were proposed to reduce emissions from land use change. The first option is to increase the sequestration potential of forests and land use mainly to compensate for the increased emission in industrialized countries 
from fossil energy use. The second option is to capture atmospheric carbon through photosynthesis and through calcification. By so doing both organic carbon and inorganic carbon in the form of calcium carbonate are returned to the soil. These are related but separate issues. And the potential of the second option through sequestration in soil and the vegetation can be as much as the amount of carbon returned to the atmosphere every year, an estimated 3 thousand million tons but for a limited period of time (20 to 25 years). A range of land management practices associated with conservation tillage appears to increase the range and numbers of meso- and microfauna in the soil; improve soil structure, permeability, moisture holding capacity and stability of the soil; and increase the amount of organic matter cycling in the soil and storing nutrients, gradually releasing them to crops. Within a few years, these practices have resulted in clearly raised land productivity and increased effect of added nutrients. The effect of the improved land management on carbon sequestration and the direct and indirect effects on biodiversity should be seen in the context of such a range of other benefits, which are in the direct interest of the land users and their households. The great expansion of land use and management systems based on zero- or minimum-tillage was driven by the widespread recognition of their direct, short- and medium-term benefits to farm households and commercial farms alike, even in the absence of transfer payments for carbon sequestration or biodiversity conservation.

Particularly, population density has shown to be highly correlated with the existence of certain land-use patterns. It is clear that demographic variables can be the most determining factors of land-use, and thus they have a high explanatory value of land use conversions. Although demographic factors are usually underestimated and bundled up under the umbrella of "social and economic factors" they should be explicitly recognized and examined in carbon sequestration projects where long-term land-use changes may be envisaged.

Reducing concentrations of carbon dioxide $\left(\mathrm{CO}_{2}\right)$ and other greenhouse gases (GHG) in Earth's atmosphere is identified as one of the most pressing modern-day environmental issues (IPCC, 2007). As a signatory country to the United Nations Framework Convention on Climate Change (UNFCCC), the United States is actively engaged in a critical international effort to find solutions to the problems posed by climate change.

Agriculture, in addition to being affected by the climate, contributes to climate change through its exchanges of GHG with the atmosphere. Thus, the management of agricultural systems to sequester atmospheric $\mathrm{CO}_{2}$ as soil organic carbon (SOC) and to minimize GHG emissions has been proposed as a partial solution to the climate change problem. In this paper, we discuss the potential role of agriculture in the United States to mitigate climate change through sequestration of carbon (C). We also identify critical knowledge gaps where further research is needed.

Carbon enters terrestrial ecosystems, including agriculture, through photosynthesis by green plants that assimilate $\mathrm{CO}_{2}$ and fix it into organic forms (Figure 1). Some $\mathrm{C}$ eventually enters the soil, where its subsequent cycling and storage among SOC and soil inorganic carbon (SIC) pools determine its residence time and ultimately its return back to the atmosphere. The rate of photosynthetic $\mathrm{CO}_{2}$ assimilation depends on soil fertility, climate, and management, which, in addition to other soil and plant factors, influence rates of $\mathrm{C}$ return to the atmosphere. Three major thrusts of GHG mitigation research in agriculture are: 
Developing management practices to enhance the assimilation of atmospheric $\mathrm{CO}_{2}$ by vegetation,

Managing the movement of $\mathrm{C}$ from the plants/animals into the soil, and

Altering the cycling of SOC to increase its residence time. Sequestering $\mathrm{C}$ within the soil organic matter (SOM) is among the best options for $\mathrm{C}$ storage in terrestrial ecosystems. Besides helping offset $\mathrm{CO}_{2}$ emissions into Earth's atmosphere, $\mathrm{C}$ sequestration into SOM provides multiple benefits, such as improved soil quality through enhanced fertility, soil structure and aggregate stability, water holding capacity, and the capacity to reduce toxic elements.

Two other gases additional to $\mathrm{CO}_{2}$; methane $\left(\mathrm{CH}_{4}\right)$ and nitrous oxide $\left(\mathrm{N}_{2} \mathrm{O}\right)$ are important agricultural GHG and deserve mentioning. Agricultural $\mathrm{CH}_{4}$ emissions occur primarily from livestock through enteric fermentation and from wetland systems like rice, with emission rates being sensitive to soil nitrogen $(\mathrm{N})$, water availability, soil $\mathrm{pH}$, and amounts and forms of SOC. Nitrous oxide emissions from agriculture are largely the result of $\mathrm{N}$ fertilizer additions. While our focus will be primarily on soil $\mathrm{C}$, we will mention non- $\mathrm{CO}_{2}$ trace gases:

To the extent their fluxes are affected by $\mathrm{C}$ sequestration management and

In the context of wetland agriculture, where $\mathrm{CH}_{4}$ fluxes are important in the $\mathrm{C}$ balance.

\section{Carbon Pools and Sequestration}

Approximately $9 \mathrm{Pg}$ (9.9 billion $\mathrm{tn})$ of $\mathrm{C}$ is presently released to the atmosphere each year from burning fossil fuels and industrial activity, and another $1.5 \mathrm{Pg}$ (1.7 billion tn) is released from deforestation and land use change (Global Carbon Project, 2009). Each year, about $60 \mathrm{Pg}$ (66 billion tn) $\mathrm{C}$ is exchanged in each direction between terrestrial ecosystems and the atmosphere. However, even as new strategies and technologies are developed, it will remain important for agriculture to continue developing and implementing successful soil $\mathrm{C}$ sequestration practices which maintain or enhance SOC and SIC pools (Figure 2). The following sections will briefly review our present knowledge of recommended management practices. At the end of each section, critical research gaps and/or development needs for enhancing $\mathrm{C}$ sequestration capabilities are identified, which are listed together in abbreviated form in Table 1.

\section{Agricultural Systems that Could Sequester Carbon}

Scientific interest in understanding what types of agricultural systems increase soil carbon and how has generated huge amounts of research on a variety of systems and on carbon dynamics in agricultural systems at different scales. Several agricultural systems have emerged as having the potential to increase soil carbon, although important details about the permanence of the carbon they sequester should be carefully considered.

\section{Conventional No-Till and Conservation Tillage}

Among the most widely studied agricultural management strategies that can increase soil carbon are no-till systems. Since soils in these systems remain undisturbed, soil aggregates remain intact, physically protecting carbon. Several studies have demonstrated that no-till can increase soil carbon rapidly; especially at the soil surface and several more detailed studies have found that this increase in carbon is linked to increases in aggregation. However, 
in order to maintain gains in soil carbon, it is important to continuously manage soils with no-till. Grandy and Robertson (2006) found that tilling a previously untilled soil quickly reversed nearly all the previously recorded gains by disrupting aggregates and exposing carbon molecules to microbial attack.

Similar to no-till, conservation tillage utilizes tillage implements less aggressive than the classic moldboard plow and requires fewer tillage passes per season such that more residues are left on the surface and disruption of soil aggregates is reduced. This approach also generally relies on chemical herbicides and genetically modified seed to reduce weed pressure. Although conservation tillage comes in many forms, several studies have demonstrated that it also can increase soil carbon by increasing soil aggregation and physically protecting carbon, but sequestration generally occurs at rates lower than no-till.

The large number of studies on carbon sequestration in no-till and conservation tillage systems seems to have generated some consensus that both these approaches can increase soil carbon. But a handful of recent meta-analyses have cast doubt on the extent of their potential. Powlson et al., (2014) highlight that the majority of studies on no-till and conservation tillage primarily demonstrate differences in carbon concentrations at the soil surface, while ignoring lower depths where more aggressive tillage systems, such as moldboard plowing, may actually be relocating carbon. Syswerda et al., (2011) demonstrated that when sampled to more extensive depths, no-till still outperformed conventional tillage systems. But a lack of data comparing soil carbon levels at depth in no-till systems versus other tillage systems from other similar trials may suggest the research community is overestimating the effectiveness of no-till systems to sequester carbon.
It is also clear that since the carbon accrued in these systems is largely due to physical protection, maintaining the same tillage regimen is important to ensuring that carbon remains sequestered. Although adoption of these strategies has increased amongst grain producers, anecdotal evidence suggests that many producers do not actually utilize no-till or conservation tillage every season, preferring to periodically till their soils with more aggressive implements to prevent problems such as compaction and to combat weeds. Furthermore, the heavy reliance on herbicides and fertilizers can negatively impact water quality, and the repeated use of glyphosate has produced a number of glyphosate-resistant weeds that often require tillage to be controlled (Duke and Powles, 2008). The potential lack of permanence of soil carbon in many conservation tillage or notill regimes coupled with the problems presented by their extensive reliance on herbicides raises question about the utility of this approach for long-term carbon sequestration.

\section{Organic No-Till}

Since organic production systems are not allowed to use herbicides or chemical fertilizers and rely on cultivation to control weeds, reducing tillage in these systems is much harder than in their conventional analogues. Conservation tillage implements that plow to a limited depth and do not invert soil like a classic moldboard plow can reduce disturbance, but the need to make multiple passes with cultivating equipment to control weeds can offset the benefits of conservation tillage implements and lead to carbon losses.

Researchers at the Rodale Institute and a number of other institutions have been experimenting with an organic no-till system, however, that if successfully developed could hold promise. The system relies on an 
implement called a roller-crimper that is used to roll over a standing cover crop in spring, flattening and crimping plants so that they die, creating mulch on the soil surface that will continue to suppress weeds throughout the growing season (Rodale Institute, 2015). Whereas most organic systems using cover crops will mow the cover crop to terminate it then till it into the soil, a roller-crimper avoids these steps, protecting the soil from disturbance. No long-term studies on the effects of this system on soil carbon pools are yet available, but soil modeling projections estimate that the carbon sequestration rates and full cycle carbon budgets, including external carbon costs, of organic no-till systems could outperform more conventional tillage systems.

Researchers testing these systems have had to deal with significant issues of weed pressure and re-growth of cover crops that affect crop productivity. Key to terminating the cover crop effectively is rolling it at the correct developmental stage. Organic no-till may also affect soil nitrogen availability, as the large amount of plant biomass it requires can cause soil microbes to rapidly uptake soil nitrogen, making it unavailable to plants (Parr et al., 2014). Organic no-till is still only being researched and practiced on a limited scale and producers and scientists are still searching for ways to overcome these issues. If reliable methods are developed, this system could lead to extensive carbon sequestration and many additional co-benefits.

\section{Cover Crops and Crop Rotations}

While conservation tillage and no-till rely on protecting soil from disturbance by tillage, other approaches simply compensate for the loss of carbon due to tillage by increasing carbon inputs from plants. The use of periodic green fallows, winter cover crops, and crop rotations that utilize semi-perennial crops, such as alfalfa, were practices long used in agriculture that fell out of use as synthetic fertilizers and pesticides became more widely used. Such practices have demonstrated benefits for weed suppression and soil fertility, and some evidence suggests that they can also lead to carbon sequestration.

Researchers found that over a 12-year period an organic management system that employed increased rotational diversity and extensive use of winter cover crops led to a significant increase in soil carbon, despite extensive tillage for weed control. Such results might be explained by a net positive difference in carbon inputs versus carbon respired as $\mathrm{CO}_{2}$, as well as improved soil biological function. In a recent meta-analysis, researchers found that more diverse crop rotations consistently have higher soil carbon and soil microbial biomass than less diverse systems, especially when cover crops were included in the rotation (McDaniel et al., 2014). Tiemann et al., (2015) further demonstrated that rotational diversity has important impacts on soil carbon accrual by improving the ability of soil microbial communities to rapidly process plant residues and protect them in aggregates. The inclusion of several different crops in a rotation also introduces a greater diversity of carbon compounds into the soil, some of which may be more resistant to decomposition. While previous thinking held that microbial processing of residues in soils eventually produced similar carbon pools and compounds, a recent laboratory experiment found that the initial chemistry of the plant residues and the microbial community had a strong influence on which carbon compounds are present in the soil. The inclusion of a diversity of crops, then, might ensure that a diversity of carbon compounds is present in the soil, improving soil carbon sequestration potential. Increasing cropping system diversity is a strategy that is relatively simple to implement in a technical sense in that it 
mostly just requires growers to plant cover crops or keep to a more consistent rotation of grain crops. Resistance to this strategy may be due to the dominance of monocultures in agriculture globally, the concomitant reduction in markets for alternative crops, and perceived risk in growing multiple crops. However, diverse crop rotations can meet the productivity of monocultures while improving environmental services and reducing the need for inputs (Davis et al., 2012).

\section{Rotational Grazing}

Recent research on grazing practices and production of meat animals, particularly cattle, has gained considerable attention for its carbon sequestration potential. When managed correctly, herds of grazing animals can maximize annual pasture biomass production and redistribute carbon throughout pastures in the more processed form of manure, leading to rapid increases in soil carbon. Methods such as Management Intensive Grazing emphasize frequently moving cattle to new pastures, high stocking densities, and preventing overgrazing such that pasture plants have continuously high biomass. In addition, this style of production generally does not require tillage, meaning soil aggregates are not disrupted and their carbon remains physically protected from disturbance.

The effectiveness of rotational grazing may be further enhanced by the addition of compost amendments to rangelands. Very thin applications of compost to grasslands under managed grazing led to substantial increases in plant biomass and a net increase in carbon sequestration. These results suggest that even small additions of composted organic matter can vastly improve the productivity of degraded rangelands and enhance their carbon sequestration capacity. There are few studies evaluating the full carbon cycle of such systems. However a meta-analysis of the existing studies on how improvements to grassland management might affect soil carbon accrual found that in the majority of the studies, conversion from croplands to grasslands and improvements in management led to greater carbon sequestration. More recently, researchers working in the southeastern US found that converting land formerly in row crops to managementintensive grazing rapidly increased soil carbon to an apparent saturation point (Machmuller et al., 2015). They also estimated that the methane emissions of cattle from enteric fermentation were offset during the early phase of rapid carbon accumulation. More extensive research on the full carbon cycle of grazing operations, including fine-scale measurement of emissions in the form of methane from cows themselves will be necessary to properly evaluate the efficacy of this approach for soil carbon sequestration, but early results are promising.

\section{Perennial Cropping Systems}

The majority of cropping systems are dominated by annual plants that rely on cycles of tillage and planting of seed to ensure sufficient productivity. By comparison, perennial plants that are capable of surviving several seasons require fewer disturbances.

Perennial cropping systems have been recently proposed as systems that could protect soil carbon well, and since perennial plants often rely on more extensive roots systems to ensure longevity, they likely produce more belowground biomass. The necessary field trials to demonstrate the carbon sequestration potential of these crops are yet to come, then, but perennial grains are conceptually promising. By comparison, agro-forestry systems that utilize tree crops and are designed to mimic forested systems while still producing food could be readily implemented but are largely underutilized and understudied. 


\section{Cropping Systems}

Recommended management practices to increase SOC in croplands include increasing cropping frequency and growing high-residue crops. Alternatively, soil C losses can be minimized by reducing soil tillage (effectiveness is soil type and crop dependent), maximizing plant water use efficiency (more efficient rotations and improved irrigation management), and application of surface mulches that shade the soil. Incorporation of perennial grasses and grass/legume mixtures can be especially effective to allocate a higher percentage of plant biomass $\mathrm{C}$ to belowground soil $\mathrm{C}$ sequestration, extend the growing season, better utilize soil water, and reduce tillage disturbance compared to annual crops. Improved practices on croplands can increase SOC sequestration rates to 0.1 to $1 \mathrm{Mg}(\mathrm{Mg}=$ megagram $=106 \mathrm{~g}$ ) $\mathrm{C} / \mathrm{ha} / \mathrm{yr}$ (89 to $890 \mathrm{lb}$ C/ac/yr), with accumulation rates diminishing as soils approach new equilibria (CAST, 2004). Higher rates are expected in the conversion of annual croplands to perennial grasses/legumes as conservation set-asides or pastures. Critical research needs for further enhancing $\mathrm{C}$ sequestration of cropped systems include:

Clarifying the interactions among tillage, climate, and soil type on $\mathrm{C}$ sequestration

Quantifying above- and below-ground plant contributions to SOC

Evaluating $\mathrm{C}$ sequestration practices for total GHG emissions, since recommended practices like incorporation of legumes or fertilizer additions, which enhance soil $\mathrm{C}$, may enhance the soil release of $\mathrm{N}_{2} \mathrm{O}$ (Table 1).

\section{Grazing lands}

Grazing land soil $\mathrm{C}$ sequestration is affected by climate, biome and management (grazing,
$\mathrm{N}$ inputs, restoration). Rangeland management with proper stocking rates, adaptive management, and destocking during drought can result in sequestration of $11 \mathrm{Tg} \mathrm{C} / \mathrm{yr}(1 \mathrm{Tg}$ $=1012 \mathrm{~g})(12$ million th $\mathrm{C} / \mathrm{yr})$ nationwide. Sequestration rates decline in rangelands over time without added inputs, and the greatest potential gains are on marginal or poorlymanaged lands (Derner and Schuman, 2007). The amount of $\mathrm{C}$ stored in improved pasturelands can be double that of cropland and can be enhanced by adjusting stocking rate, plant species, and fertilizer additions; although, the later can reduce the $\mathrm{C}$ advantage through increased emissions of $\mathrm{N}_{2} \mathrm{O}$ (Franzluebbers, 2005). Rates of SOC sequestration under best management practices range from 0.070 to $0.30 \mathrm{Mg} \mathrm{C} / \mathrm{ha} / \mathrm{yr}$ (62 to $270 \mathrm{lb} \mathrm{C/ac/yr)} \mathrm{for} \mathrm{rangelands} \mathrm{and} \mathrm{from}$ 0.30 to $1.4 \mathrm{Mg} \mathrm{C} / \mathrm{ha} / \mathrm{yr}$ (270 to $1200 \mathrm{lb} / \mathrm{ac} / \mathrm{yr}$ ) for pastures. Critical research needs in grazing land soil C sequestration include:

Quantifying $\mathrm{C}$ sequestration in arid shrub lands

Evaluating forage species mixtures for optimizing $\mathrm{C}$ sequestration and minimizing non- $\mathrm{CO}_{2}$ trace gas emissions

Quantifying interactions of management with climate on $\mathrm{C}$ sequestration (Table 1).

\section{Agroforestry}

Agroforestry is the intentional integration of woody plants into crop and livestock systems to improve soil, water and air quality, and wildlife habitat while supporting sustainable production of food, feed, fiber, and energy (Garrett, 2009). It represents a significant opportunity for sequestering $\mathrm{C}$ on agricultural lands in that a substantial proportion of the $\mathrm{C}$ is sequestered in woody biomass, thus creating a system that sequesters a large amount of $\mathrm{C}$ per unit area and for a longer duration than many other practices. Nair and Nair (2003) 
estimated areas either currently under, or which could potentially be brought under, agroforestry practices to encompass 80, 70, and 85 Mha (200, 170, and 210 million ac) for alley cropping, silvopasture, and windbreaks; respectively, with an additional 0.8 and 2.4 million $\mathrm{km}(0.5$ and 1.5 million $\mathrm{mi}$ ) of forested riparian and conservation buffers, respectively. Potential $\mathrm{C}$ storage for temperate agroforestry ranges from 15 to $198 \mathrm{Mg} \mathrm{C} / \mathrm{ha}$ (6.7 to $88 \mathrm{tn} \mathrm{C} / \mathrm{ac}$ ) or approximately $90 \mathrm{Tg}$ C/yr (99 million tn $\mathrm{C} / \mathrm{yr}$ ) by 2025. Critical research needs in agroforestry include:

Quantifying C dynamics in agroforestry systems

Developing effective strategies for measuring and monitoring $\mathrm{C}$ sequestration in soil and woody components

Developing/implementing a national inventory of agroforestry (Table 1).

\section{Horticulture}

Little attention has been paid to $\mathrm{C}$ sequestration in vegetable, orchard, and vineyard crops. The timing of critical management practices to achieve optimum market timing can impact these high-value cash crops and dampen efforts to sequester soil $\mathrm{C}$. However, limited research suggests promising uses of cover crops for promoting increased soil C storage in vegetable and vineyard systems. Further, cover crops offer many benefits beyond $\mathrm{C}$ sequestration, such as increasing soil fertility and enhancing disease control (Delgado et al., 2007). More research is needed in horticultural systems to:

Evaluate potentially feasible horticultural management practices for storing soil $\mathrm{C}$

Quantify C sequestration in promising horticultural systems
Further evaluate benefits of conservation practices beyond $\mathrm{C}$ sequestration (Table 1).

\section{Turf grass}

Many land areas previously used for agriculture have now become part of the urban landscape, including lands that have been converted to C-sequestering turf grasses. Rates of SOC sequestration under turf have a fairly broad range, from 0.32 to $1 \mathrm{Mg} \mathrm{C} / \mathrm{ha} / \mathrm{yr}$ (290 to $890 \mathrm{lb} / \mathrm{ac} / \mathrm{yr})$. Using the lowest rate of sequestration of about $0.32 \mathrm{Mg} \mathrm{C} / \mathrm{ha} / \mathrm{yr}$ (290 $\mathrm{lb} \mathrm{C} / \mathrm{ac} / \mathrm{yr}$ ) applied to the $16 \mathrm{Mha}$ (40 million ac) of turf grass reported by Milesi et al., (2005), we estimate that about $5 \mathrm{Tg}$ (5.5 million tn) $\mathrm{C}$ are sequestered by turf grass systems across the continental United States each year. Critical needs in turf grass include:

Knowledge to incorporate the combined effects of urbanized land area expansion with agricultural land area losses into national estimates of soil $\mathrm{C}$ sequestration

Improved quantification of rates and areas for $\mathrm{C}$ sequestration under various urban land uses

Obtaining a better understanding of the role that growing turf grass may have on emissions of other GHGs such as $\mathrm{N}_{2} \mathrm{O}$ and $\mathrm{CH}_{4}$ (Table $1)$.

\section{Wetlands and Organic Soils}

Although organic soils and wetland agriculture each constitute $1 \%$ or less of cropped areas in the United States, their high rates of GHG emissions deserve special attention. Organic soils develop under waterlogged conditions, where lack of oxygen inhibits organic matter decomposition.

However, with drainage, microbial oxidation of the organic matter causes them to subside and release $\mathrm{CO}_{2}$ at high rates. However, 
estimated emissions rates have dropped about $43 \%$ (3.95 Mg C/ha [1.76 tn C/ac]) following declining rates of soil subsidence in more recent years. Although it is not feasible to consider $\mathrm{C}$ sequestration in such soils, reducing the emissions of $\mathrm{GHG}$ is an important goal. Management to combat GHG emissions includes maintaining high water tables and selection of crops that can tolerate periodic flooding. Unfortunately, high watertable strategies, while reducing organic matter decomposition and reducing $\mathrm{CO}_{2}$ emissions, may enhance emissions of both $\mathrm{CH}_{4}$ and $\mathrm{N}_{2} \mathrm{O}$.

The anaerobic conditions of flooded rice fields result in methanogenic bacteria generating $\mathrm{CH}_{4}$ as well as $\mathrm{CO}_{2}$, formed by oxidation of $\mathrm{CH}_{4}$ near plant roots. Water table level, temperature, fertilization, irrigation, organic matter (plant residues), and season can all affect emission rates. Conditions in rice fields that diminish $\mathrm{CH}_{4}$ synthesis and release may promote emission of $\mathrm{N}_{2} \mathrm{O}$, thus complicating the development of best management practices that can consider both gases. Strategies to reduce $\mathrm{CH}_{4}$ (and $\mathrm{N}_{2} \mathrm{O}$ ) emissions from rice fields include timing of midseason drainage, split fertilizer applications, nitrification inhibitors, avoiding incorporation of fresh organic matter and plant residues, and selection of rice cultivars with low gas transport and low rates of root exudation. Research is needed to develop strategies that minimize emissions of both $\mathrm{CH}_{4}$ and $\mathrm{N}_{2} \mathrm{O}$ for:

Rice cultivation

Other major crops grown on organic soils (Table 1).

\section{Emerging Issues}

Implementation of agricultural $\mathrm{C}$ sequestration and non- $\mathrm{CO}_{2}$ GHG mitigation practices must take into account two important emerging issues:
Biofuels

The potential impact of climate change and rising $\mathrm{CO}_{2}$ on $\mathrm{GHG}$ mitigation strategies.

\section{Biofuels}

A keen interest exists to develop sustainable energy technologies from cellulosic biofuels (Robertson et al., 2008). However, a number of concerns have been raised about possible environmental problems arising from intensification of agriculture (e.g.; soil erosion, decrease in soil quality and productivity, loss of nitrate and phosphorous, decline in air quality, decline in biodiversity, increased loss of forests to compensate for cropland lost to biofuel production), some of which may compromise the overall goal of enhancing agro-ecosystem $\mathrm{C}$. There are many gaps in our knowledge about the potential impact of biofuel energy crops on SOC. Top research priorities include:

Evaluating how SOC responds to annual and perennial biofuel cropping systems, including operations on marginal lands;

Clarifying relationships among soil $\mathrm{C}$ storage and fluxes of non- $\mathrm{CO}_{2}$ GHGs for biofuel operations; and

Examining the implications of biofuel production on $\mathrm{C}$ storage in Conservation Reserve Program (CRP) lands, grass lands, and forested lands (Table 1).

\section{Climate Change Feedbacks and C Sequestration}

As we become more confident about its trajectory, we are learning that climate change itself may constrain the very practices designed to curb GHG emissions and enhance $\mathrm{C}$ sequestration. Rising atmospheric $\mathrm{CO}_{2}$ generally increases plant production (Runion 
et al., 2009), which in turn could enhance SOC stocks through greater transfer of plant $\mathrm{C}$ into the soil. However, rising $\mathrm{CO}_{2}$ often results in higher soil respiration losses, which would diminish the benefit of increased plant production on total system C. Rising temperatures in cooler regions may also increase growing-season length, prolong and enhance biological activity, and enhance net $\mathrm{C}$ uptake (Luo et al., 2007). However, extension of the growing season at a time of year when daily light fluxes are already low will have limited benefits for $\mathrm{C}$ uptake, especially at northerly latitudes, since photosynthesis will become increasingly light limited. Furthermore, the fertilization effect of $\mathrm{CO}_{2}$ on plant productivity observed in short-term experiments may not be sustained because soil nutrients eventually limit plant responses to $\mathrm{CO}_{2}$, especially in native systems without fertilizer additions. Climate change may further constrain, eliminate, and even reverse positive production benefits of higher $\mathrm{CO}_{2}$ since higher temperatures enhance evaporative demand and lead to desiccation. By itself, warming also leads to higher SOM decomposition rates, which may further increase $\mathrm{CO}_{2}$ emissions. Thus, while climate change has likely stimulated $\mathrm{C}$ sequestration in the recent past, continued warming may reduce terrestrial $\mathrm{C}$ sequestration later in this century (Heimann and Reichstein, 2008). Critical research needs include:

More process-level research to evaluate how multiple climate change factors affect the functioning of important agro-ecosystems,

Modeling exercises that incorporate the latest findings from climate change experiments and project long-term impacts on $\mathrm{C}$ sequestration, and

Observational/monitoring systems for tracking climate change impacts on agro-ecosystem attributes (e.g.; plant cover, vegetation type) that are likely to be good indicators of $\mathrm{C}$ storage potential (Table 1).

\section{Purposes and modes of carbon sequestration}

$\mathrm{CO}_{2}$ is an important greenhouse gas. Its concentration in the atmosphere has increased from $280 \mathrm{ppm}$ to $365 \mathrm{ppm}$ in the last 150 years, because of strongly increased use of fossil fuel, deforestation and cement production. Further increase, together with that of some other trace gases $\left(\mathrm{CH}_{4}, \mathrm{~N}_{2} \mathrm{O}\right.$, among others) will most likely result in an increase of global temperatures with $2^{\circ} \mathrm{C}$ by the year 2100, an increase in sea level of 50 $\mathrm{cm}$ and an increase of average rainfall with $10-15 \%$ (IPPC, 1996). Such a change is considered to be negative for the global human life-supporting system. Therefore a Framework Convention on the Control of Climate Change (FCCC) was developed, with the Kyoto Protocol of 1997 as first practical agreement on controlling the national emissions of $\mathrm{CO}_{2}$ and other greenhouse gases.

The Kyoto Protocol recognizes that reduction can be effectuated through curbing of gross $\mathrm{CO}_{2}$ emissions - difficult to be realized in industrialized countries with a growing economy, but also by increasing the $\mathrm{CO}_{2}$ uptake in ocean waters and on land, thereby reducing the net emissions. The uptake on land can be through increasing the biomass of vegetation (planting of forests), through enhancing the organic carbon in soils, or a combination of the two. This terrestrial uptake or "sequestration" can be in and between industrialized countries themselves ("joint implementation", already formal) or in developing countries through use of environmental protection funds of any industrial country ("Clean Development Mechanism"; proposed). The forest planting scenario has as advantage that biofuels and construction materials can be harvested 
periodically, replacing fossil fuel, cement etc. The sequestering of carbon in organic matter of agricultural soils would result in additional $\mathrm{CO}_{2}$ storage, as well as an increase in quality of the soil for the production of food, fibre, feed, etc. on a sustainable basis. More soil organic matter (SOM) increases the storage capacity for plant nutrients, makes the plant less susceptible to droughts and provides more resistance to physical land degradation through strengthening of the soil structure.

The total carbon already stored in the plantsoil complex varies per biome, per agroecological zone and per predominant land use system. But in general there is more stored in the soil as soil organic carbon (SOC) than in the above and below ground vegetational biomass. Even in humid tropical forests there is as much carbon in the soil as in the whole above-ground luxurious vegetation. In its atmospheric concentrations, $\mathrm{CO}_{2}$ is not a pollutant or a dangerous gas. It is an essential element for plant growth and is right now in the minimum if the other essential conditions (temperature, daylight, moisture, nutrients, foothold) are adequate. During the growing season $\mathrm{CO}_{2}$ becomes bound to the green plant through the daytime assimilation process, while at night time the plant and the surrounding soil releases again some $\mathrm{CO}_{2}$ through respiration. In summertime the net $\mathrm{CO}_{2}$ uptake in the terrestrial biosphere is large, and as a consequence the $\mathrm{CO}_{2}$ concentration in the atmosphere decreases temporarily. The summer-winter difference in concentration is most conspicuous where the land mass is largest and the other growth conditions have a large seasonal difference.

Being normally the limiting factor for plant growth, any increase in atmosphere $\mathrm{CO}_{2}$ concentration causes an increase in plant growth. This is the so-called " $\mathrm{CO}_{2}$ fertilization effect"; which is particularly active in $\mathrm{C}_{4}$ plants, such as wheat, rice and most woody plants. It would account for the "missing Carbon sink" of $1.5 \mathrm{Tg}$ per year of global carbon flux modellers. Higher Carbon concentrations also cause an increase in the water use efficiency of plants through regulation of stomatal conductance. This is the so-called " $\mathrm{CO}_{2}$ anti-transpiration effect" which is particularly active in $\mathrm{C}_{3}$ plants such as sorghum, maize and many tropical grasses. Both effects, locally combined with increased Nitrogen availability from atmosphere deposition, form a so-called "negative feedback" mechanism in the human-induced forcing of climate change. They are a startbonus at efforts to sequester $\mathrm{CO}_{2}$ in vegetation and soils. One can argue that they are a blessing-in-disguise at human-induced global change, and that the earth is moving to a higher trophic level - as it has been in some periods - this time concurrently with, and as a consequence of the strong global human population increase and its basic needs for well-being. It is already known for some ten years that planted or natural forests in temperate and cool regions grow faster than before (when not too old, on too poor soil, or too near polluting sites). Only in the last 2-3 years it has become apparent that nowadays also the primary forests in tropical regions may act as a net sink of $\mathrm{CO}_{2}$, instead of just a store (except in situations of periodic drought, such as El Niño). The biodiversity and local climatological/hydrological regulative functions of these forests can be safeguarded easier if this additional function of an active carbon sink will be confirmed scientifically, and recognized politically.

The above surmised indirect positive human influence on forest growth will not be openended. Trees will not grow into heaven; rather, they will have earlier senescence and end up, for a good part, in increased stable organic matter in the forest soil (if selective timber harvesting from these natural forests takes place) then the net increase may be negligible. 
Agricultural soils have usually less soil organic matter (SOM) and therefore less soil organic carbon (SOC) than their natural counterparts. They are degraded in the biological sense, and it is a feasible proposition to lead them back towards their original SOC level through adapted practices.

In some situations the agricultural soil has historically increased its SOC. Accidental or conscious lateral import of SOM to the surroundings of towns and villages, with their century long, intensive and manure-based agriculture, has produced soils with approx. double the natural amount of stable SOM. It has moreover a higher colloidal activity level in the form of higher nutrient exchange capacity (CEC). This process can conceivably be emulated, as one of the measures to sequester carbon in agricultural soils, in a matter of decades instead of centuries, and without depleting the SOM of the wider countryside.

Carbon sequestration in vegetation (forests), in biofuel, crops and in soils should be integrated in over-all sustainable rural development, with full participation of the local population; "Kyoto forests" and "Kyoto lands" should not become foreign bodies. Soil Organic Matter enhancement, where necessary with other soil conditioners such as lime and rock-phosphate, should be considered as a capital investment in soil and land quality.

\section{Integrated approaches}

One possible avenue of operationalization of the mechanism is the so-called "Integrated Ecosystem Management (IEM)" approach which is being experimented with, and has worked well, so far, in Mexico and Ecuador as well as in some areas of Ontario in Canada. It is a watershed consortium which embraces several components and involves key representatives from different sectors, the interaction of government at various levels, including the local government, the municipality, Universities, research NGOs and local communities. Participatory decisionmaking from the start is the key to the success of this approach (Figure 3).

The level of intervention was also discussed and there was a broad understanding that the interventions should be at the community level rather than the level of individual farmers. There is a need for a holistic approach which considers the provision of economic goods which have an impact at the community level.

Interventions at the community level rather than the level of individual farmers can help overcome two problems simultaneously, firstly by bundling small contributions to make them attractive to international investors, and secondly by avoiding a collision with the "additionality" criteria established by the Clean Development Mechanism. According to the "additionality" criteria, improved practices, which are being adopted by individual farmers in a region for other reasons than carbon sequestration, become the "baseline" for that region and are not further eligible for funding.

At the community level, however, it is possible to negotiate carbon sequestration as a package and then induce farmers to adopt them gradually.

Many studies have shown that in order to link the farm level or village level to the biogeochemical cycles it is useful to include the watershed or landscape level because it allows the inclusion of some of the externalities which are not visible or treatable effectively by examining only the farm level. As a planning unit to represent local markets, watershed is a very appropriate level that should be considered in an integrated study (Table 2). 
Table.1 Critical research needs for developing and implementing carbon sequestration and non$\mathrm{CO}_{2}$ greenhouse gases mitigation practices

\begin{tabular}{|c|c|}
\hline Topics & Critical needs \\
\hline \multicolumn{2}{|r|}{ Agricultural sectors } \\
\hline \multirow[t]{3}{*}{ Cropping systems } & Clarify tillage and environnent interactions on soil $\mathrm{C}$ \\
\hline & Quantify above- and belowground C contributions \\
\hline & Evaluate $\mathrm{C}$ practices for total GHG emissions \\
\hline \multirow[t]{3}{*}{ Grazinglands } & Quantify C sequestration in arid shrublands \\
\hline & $\begin{array}{l}\text { Evaluate species mixtures for soil C sequestration and minimizing total } \\
\qquad \text { GHG emissions }\end{array}$ \\
\hline & Evaluate management and environment interactions on $\mathrm{C}$ sequestration \\
\hline \multirow[t]{3}{*}{ Agroforestry } & Quantify $\mathrm{C}$ dynamics in agroforesty systems \\
\hline & $\begin{array}{l}\text { Find effective strategies for measuring/monitoring } \mathrm{C} \text { sequestration in soil } \\
\text { and woody components }\end{array}$ \\
\hline & Develop and implement national inventory \\
\hline \multirow[t]{3}{*}{ Horticulture } & Evaluate feasible practices for storing soil C \\
\hline & Quantify C sequestration in promising systems \\
\hline & Evaluate benefits beyond $\mathrm{C}$ sequestration \\
\hline \multirow[t]{3}{*}{ Turfgrass } & Incorporate effects of urbanization in national $\mathrm{C}$ estimates \\
\hline & Quantify $\mathrm{C}$ sequestration for various urban uses \\
\hline & $\begin{array}{l}\text { Evaluate the role of turfgrass systems on the emission of non- } \mathrm{CO}_{2} \text { trace } \\
\text { gases }\end{array}$ \\
\hline \multirow[t]{2}{*}{$\begin{array}{l}\text { Potential nigh fiux } \\
\text { areas }\end{array}$} & $\begin{array}{l}\text { Perform research and management for minimizing } \mathrm{CH} 4 \text { and } \mathrm{N}_{2} \mathrm{O} \text { fluxes in } \\
\text { rice and other crops grown on organic soils }\end{array}$ \\
\hline & Regional and national scale analyses \\
\hline \multirow[t]{3}{*}{$\begin{array}{c}\text { Measurements/mo } \\
\text { nitoring }\end{array}$} & $\begin{array}{l}\text { Develop low-cost C/GHG monitoring systems and integrate with soil } \\
\text { sampling network, modeling, and remote sensing }\end{array}$ \\
\hline & $\begin{array}{l}\text { Improve and develop models of C/GHG fluxes from different } \\
\text { agricultural sectors for scaling to regional and national }\end{array}$ \\
\hline & Enhance remote sensing tools for quantifying C/GHG fluxes \\
\hline \multirow[t]{2}{*}{ Databases } & Expand soil C/GHG monitoring networks \\
\hline & Develop national agricultural C/GHG database \\
\hline \multirow{4}{*}{ Bio-fuels } & Emerging issues \\
\hline & Evaluate SOC responses to biofuel operations, including marginal lands \\
\hline & Clarify relationships between $\mathrm{C}$ storage and non- $\mathrm{CO}_{2} \mathrm{GHG}$ fluxes \\
\hline & $\begin{array}{c}\text { Evaluate implications of biofuel on C stores of CRP, grasslands, and } \\
\text { forests }\end{array}$ \\
\hline \multirow[t]{3}{*}{ Climate change } & Perform process-level research on multiple climate change factors \\
\hline & $\begin{array}{l}\text { Develop models to predict future impacts of climate change on } \mathrm{C} \text { and } \\
\text { GHG fluxes }\end{array}$ \\
\hline & $\begin{array}{l}\text { Develop observational and monitoring systems for tracking climate } \\
\text { change impacts on agroecosystem C stores }\end{array}$ \\
\hline
\end{tabular}


Table.2 Strategies of $\mathrm{C}$ sequestration in soil

\begin{tabular}{|c|c|c|}
\hline S. No. & Strategy & Practices \\
\hline & \multicolumn{2}{|r|}{ Reduce losses from soil due to } \\
\hline 1. & Accelerated erosion & $\begin{array}{c}\text { Mulch farming, conservation tillage cover crops, terraces, } \\
\text { low stocking rate, improved pasture }\end{array}$ \\
\hline 2. & Mineralization & $\begin{array}{c}\text { Enhancing aggregation, deep placement of biomass, } \\
\text { providing N, P and S for humification }\end{array}$ \\
\hline \multirow[t]{2}{*}{3.} & Decomposition & Increasing lignin content in plant \\
\hline & \multicolumn{2}{|c|}{ Increase carbon concentration in soil by } \\
\hline 1. & Returning biomass to soil & $\begin{array}{l}\text { Mulch farming, conservation tillage use of biosolids on land, } \\
\text { compost etc }\end{array}$ \\
\hline 2. & Enhance water use efficiency & $\begin{array}{l}\text { Soil-water conservation, water harvesting, supplemental } \\
\text { irrigation through appropriate techniques }\end{array}$ \\
\hline \multirow[t]{2}{*}{3.} & $\begin{array}{l}\text { Improving nutrient use } \\
\text { efficiency }\end{array}$ & $\begin{array}{l}\text { Integrated nutrient management, new formulations, judicious } \\
\text { rate and timing of application, precision farming }\end{array}$ \\
\hline & \multicolumn{2}{|c|}{ Improvement in crop yield and biomass production } \\
\hline 1. & $\begin{array}{l}\text { Improved cropping/farming } \\
\text { system }\end{array}$ & $\begin{array}{c}\text { Improved varieties, proper crop rotations and crop } \\
\text { combinations }\end{array}$ \\
\hline 2. & $\begin{array}{l}\text { Cultivars with high lignin } \\
\text { content and deep root system }\end{array}$ & Biotechnology, soil management, P placement, liming \\
\hline 3. & High yield and biomass & IPM, INM \\
\hline
\end{tabular}

Fig.1 The terrestrial carbon cycle. Inputs of carbon (C) into the soil organic C (SOC) pool originate from the fixation of atmospheric $\mathrm{CO}_{2}-\mathrm{C}$ through photosynthesis by plants into simple sugars, and subsequently into the more complex materials (i.e., cellulose and lignin), eventually deposited in their leaves, stems, and roots. Plant material and its organic $\mathrm{C}$ can be consumed by animals or become humified into soil organic matter (SOM), which contains SOC, through the action of microorganisms. Carbon storage as SOC is controlled by the soil environment and the quality of the organic matter in which the carbon resides. Decomposition is the biological conversion of organic matter into more oxidized constituents, including $\mathrm{CO}_{2}$, which is released back to the atmosphere. Decomposition rates are affected by soil structure and by soil temperature and moisture conditions.

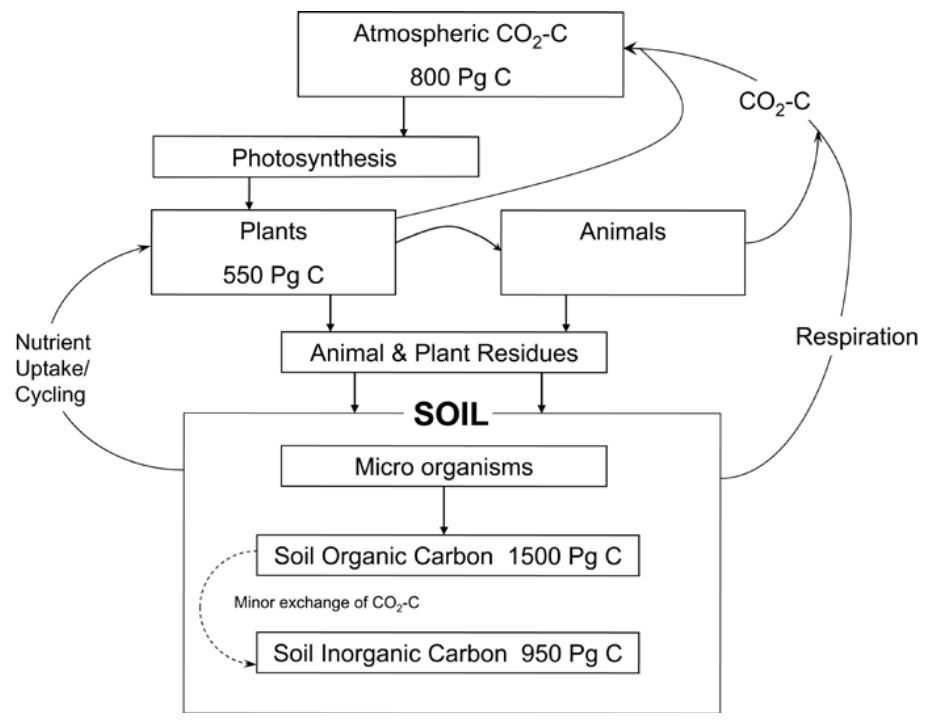


Fig.2 Principal global $\mathrm{C}$ pools and fluxes between them $(1 \mathrm{Pg}=$ petagram $=1015 \mathrm{~g}=$ thousand million tons)

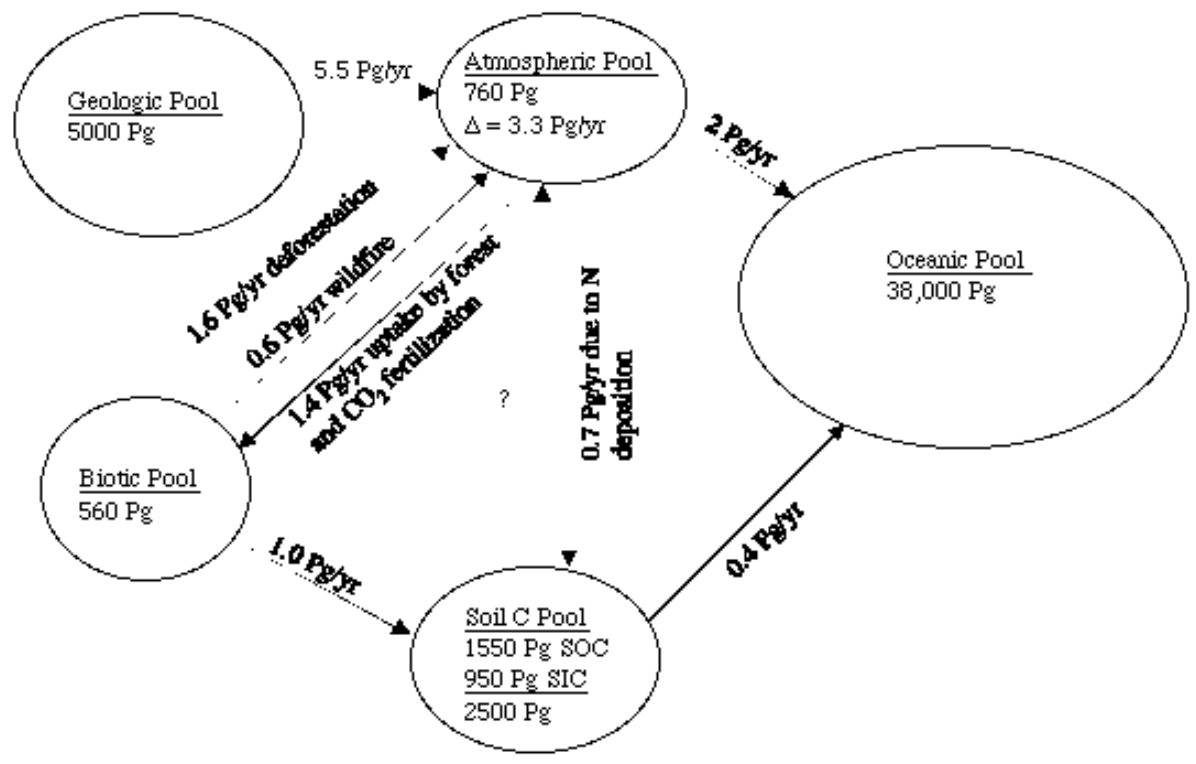

Fig.3 Inter-Relation between food security, natural resources management and environment

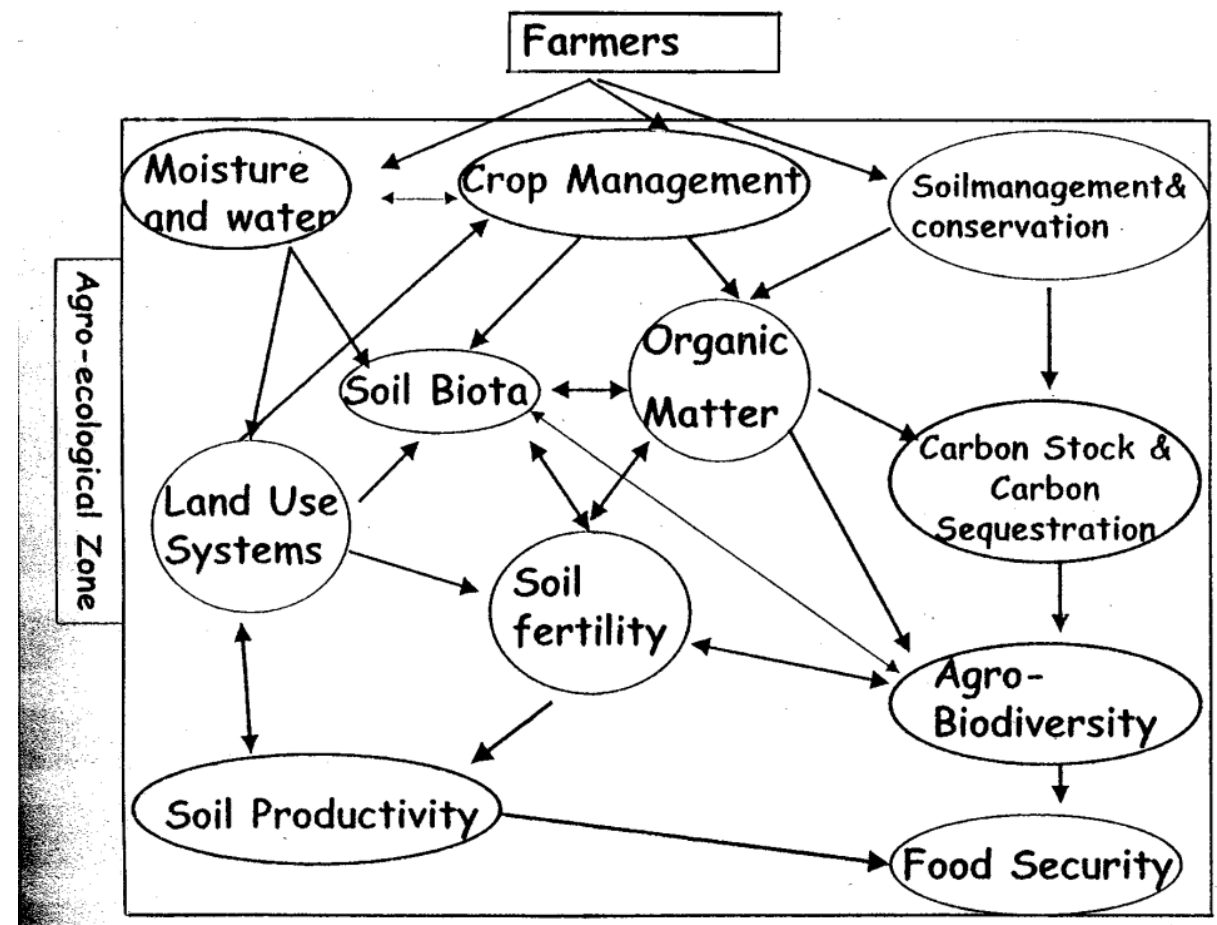

Inter-Relation between food security, natural resources management and environment

The incentive scheme should be applied at the community level. It is at such a level that the overall balance of exploitation and degradation versus growth and storage across the landscape is maintained as an aggregate of individual farms. This is particularly true of 
communal forest lands. This is a difficult task which requires a lot of imagination and ingenuity.

There is also a need to prioritize, that is to identify the hot spots where the actions will bring immediate returns. Replicability and upscaling become the major challenge and are linked not only to incentive per se, but also to the technology available at the level of the farmers and to existing infrastructure and the economic goods which are available to the farmer.

It is doubtful, however, whether such mechanisms will have some effect on the $\mathrm{CO}_{2}$ concentration without any qualitative statements whether it should increase, be stabilized or decrease.

\section{Co-Benefits}

In addition to mitigating carbon emissions, increasing soil carbon can have profound effects on soil quality and agro-ecosystem productivity. Soil carbon plays important roles in maintaining soil structure, improving soil water retention, fostering healthy soil microbial communities and providing fertility for crops (Schmidt et al., 2011).

These improvements are well documented and have generated a consensus that improvements to soil carbon are key to improving agricultural systems as a whole. While uncertainties may remain about the potential of agricultural soils to act as a carbon sink, the vast number of co-benefits should remain an incentive to modify agricultural practices to increase soil carbon in their own right.

\section{Reducing Other Greenhouse Gas Emissions in Agriculture}

A side from net soil carbon sequestration capacity, there are several other important considerations in evaluating agricultural systems for their climate mitigation potential and feasibility. While carbon dioxide is the largest driver of anthropogenic climate change, and has been the main focus of mitigation efforts, there are other greenhouse gases (GHGs) that make significant contributions to climate change. These gases, particularly methane $\left(\mathrm{CH}_{4}\right)$ and nitrous oxide $\left(\mathrm{N}_{2} \mathrm{O}\right)$, are commonly emitted from soils and should be considered in studies of agricultural climate mitigation potential. Agricultural activity is responsible for about $70 \%$ of anthropogenic $\mathrm{N}_{2} \mathrm{O}$ emissions (World Bank, 2015a) and $40 \%$ of $\mathrm{CH}_{4}$ emissions globally (World Bank, 2015b). These greenhouses gases have significantly higher radiative forcing and longer atmospheric residence times than $\mathrm{CO}_{2}$. Although neither of these gases can be taken up directly by plants and sequestered in soils the same way as $\mathrm{CO}_{2}$, it is important to consider the emission of these GHGs when evaluating different agricultural practices for their potential to sequester carbon. Research on $\mathrm{N}_{2} \mathrm{O}$ and $\mathrm{CH}_{4}$ emissions is a relatively new field, but there are clearly a few factors that strongly influence emissions of either gas from soils. $\mathrm{N}_{2} \mathrm{O}$ emissions increase when soils become saturated with water, creating anaerobic (i.e., low oxygen) soil conditions in which bacteria are forced to use nitrate instead of oxygen as a final electron acceptor in metabolic processes, producing $\mathrm{N}_{2} \mathrm{O}$. Emissions are further increased when high soil moisture is coupled with high temperatures. Emissions of $\mathrm{N}_{2} \mathrm{O}$ therefore tend to occur in pulses that are strongly coupled with wetting/drying cycles in soils during the growing season. During these pulses, the total amount of nitrate in the soil strongly influences the total amount of $\mathrm{N}_{2} \mathrm{O}$ emissions that will occur, meaning agricultural practices that tend to saturate soil with nitrate produce higher $\mathrm{N}_{2} \mathrm{O}$ emissions. In conventional production, the heavy use of fertilizer can lead to excess amounts of nitrate 
in soils that go unutilized by crops that are frequently off-gassed as $\mathrm{N}_{2} \mathrm{O}$. Similarly, soils previously planted to nitrogen-fixing crops such as beans or legume cover crops may increase the amount of total nitrogen in the soil, which can lead to increases in nitrate and potential increases in $\mathrm{N}_{2} \mathrm{O}$ emissions (Basche et al., 2014). Optimizing the delivery of nitrogen to crops and ensuring that excess fertilizer is not applied to crops can significantly reduce the potential for $\mathrm{N}_{2} \mathrm{O}$ production. The primary sources of methane emissions in agriculture are enteric fermentation in livestock, particularly cattle, and methane generation from soils in rice paddy systems. Enteric fermentation is the process by which cattle digest feed in their rumens with the aid of symbiotic microbes, including methanogens.

These methanogens are most active in the digestion of complex carbohydrates, meaning cattle fed higher proportions of hay generate more methane. Very recent research has produced a feed supplement that inhibits methane production in the cow's gut, reducing methane production by as much as $30 \%$, but reducing emissions in livestock production is generally difficult. Instead, emissions can be offset within the same production systems through the use of rotational grazing practices that increase soil carbon (Machmuller et al., 2015). Perhaps more importantly, reducing or slowing the growth of global livestock production would also reduce the amount of methane produced from agriculture but is contingent on market forces and consumer choices.

Methane emissions are particularly high in the production of paddy rice, which is typically flooded during production. Flooding fields reduces soil oxygen levels, increasing soil methanogen activity, which utilize $\mathrm{CO}_{2}$ instead of oxygen as a final electron acceptor for metabolic activities. The widespread production of paddy rice and the importance of rice as a staple crop around the world account for the considerable size of rice's GHG footprint. Researchers have recently produced a genetically modified variety of rice that releases fewer carbon compounds into the soil via its roots, thereby reducing the amount of $\mathrm{CO}_{2}$ that methanogens would utilize ( $\mathrm{Su}$ et al., 2015). But a simpler approach to reducing methane emissions in rice systems would be to drain fields mid-season when flooding is less necessary for production. These practices do not lead to direct sequestration of $\mathrm{CO}_{2}$, but they are important to consider since nitrous oxide and methane represent a large fraction of total GHG emissions from agriculture. Some of these changes could be easily implemented, rapidly reducing agriculture's footprint and shifting agriculture's carbon balance in a more favorable direction.

\section{The role of farmers}

The starting point, it was emphasized during the discussions, is to understand that ultimately land use decisions are made by individual land users, the individual farmer, the individual pastoralist, and other individuals and not by governments, NGOs, the World Bank, FAO or IFAD. Only land users themselves can change their land use or land management practices, and except in the case of force or coercion, they will only do so after they have clearly perceived adequate short-term and ongoing benefits from such a change to themselves or to their households. Once that is the case, improved land management methods may spread rapidly. Land users take decisions on the basis of a range of influences - the available technology, the policies they face, their particular household characteristics. These decisions are only indirectly affected by government policies or by World Bank projects, or by IFAD projects. Activities must be profitable as the costs and benefits to the farmers are the 
critical point in their decision making. If this is not taken into account the initiatives are likely to fail as they have failed in the past. Farmers' decisions will affect land quality which in turn affects crops and livestock production, and consequently the farmers have a very strong incentive to take land quality improvements into consideration. Offsite costs linked to global problems and benefits will not be taken into consideration by farmers unless incentives are provided. Now the big difference here is that, whereas local governments have an incentive to do something about national offsite costs by trying to create a policy framework that discourages degrading practices and encourages conserving practices, this is not the case for the global problems.

The various initiatives to establish prototype carbon funds, joint implementation activities and the various mechanisms such as the GEF, by which these benefits are translated into money going into the system to try to change these land use decisions in an appropriate way, are very important discussions. However, at the end of the day there is no direct way to effect farmers' decision on land use. The same problems that governments have been facing in trying to motivate farmers to adopt particular land use practices for national reasons will affect any effort to get farmers to act for global reasons. The crucial point is the involvement from an early stage of the stakeholder and identification and involvement of the stakeholders in the planning unit whether they may be macrowatershed, watershed or the farm. Peoples' participation is required and the land users need to be involved, not only in the present stage but also in the short and long term. In trying to move from macro-planning to the farm level planning the key question is to develop some type of participatory process with the farmer.
In agriculture, $\mathrm{C}$ sequestration research has tended to focus primarily on productive cropping systems. Too few experiments have specifically addressed best management practices for improving soil $\mathrm{C}$ storage, and fewer yet evaluate practices to reduce emissions of non- $\mathrm{CO}_{2}$ trace gases. Organic soils and wetlands present especially complex management challenges since they involve significant emissions of more than one GHG, and practices that reduce emissions of one GHG may stimulate another. Agro-forestry contributions to GHG mitigation have not been considered in national inventories. Addressing these researches needs, including the challenges presented by biofuels development and climate change feedbacks on agricultural GHG emissions will be critical for giving the necessary tools to mitigate climate change. Continued progress on scaling and monitoring methodologies will be essential to implement regional/national analyses and assessments that climate change policies and protocols will demand.

\section{References}

Basche, A.D., Miguez, F.E., Kaspar, T.C. and Castellano, M.J. 2014. Do cover crops increase or decrease nitrous oxide emissions? A meta-analysis. J. Soil Water Conserv. 69(6): 471-482.

CAST (2004). Climate Change and Greenhouse Gas Mitigation: Challenges and Opportunities for Agriculture. Ames, IA: CAST.

Davis, A.S., Hill, J.D., Chase, C.A., Johanns, A.M. and Liebman, M. 2012. Increasing Cropping System Diversity Balances Productivity, Profitability and Environmental Health. PLoS ONE 7(10): e47149.

Delgado, J.A., Dillon, M.A., Sparks, R.T. and Essah, S.Y.C. 2007. A decade of advances in cover crops: Cover crops with limited irrigation can increase yields, crop quality, and nutrient and 
water use efficiencies while protecting the environment. Journal of Soil and Water Conservation 62:110A-117A.

Derner, J.D. and Schuman, G.E. 2007. Carbon sequestration and rangelands: $\mathrm{A}$ synthesis of land management and precipitation effects. Journal of Soil and Water Conservation 62:77-85.

Duke, S.O. and Powles, S.B. 2008. Glyphosate: a once-in-a-century herbicide. Pest Manag. Sci. 64(4): 319-325.

FAO. 1999. Prevention of land degradation, enhancement of Carbon sequestration and conservation of Biodiversity through land use change and Sustainable land management with a focus On latin america and the caribbean. Proceedings of an IFAD/FAO Expert Consultation IFAD, Rome, Italy, 15 April 1999; 113 p.

Franzluebbers, A.J. 2005. Soil organic carbon sequestration and agricultural greenhouse gas emissions in the southeastern US. Soil and Tillage Research 83:120-147.

Garrett, H.E. 2009. North American Agroforestry: An integrated Science and Practice. 2nd ed. Madison, WI: American Society of Agronomy.

Global Carbon Project. 2009. Carbon budget 2008: An annual update of the global carbon budget and trends. http://www.globalcarbonproject.org/carb onbudget/index.htm

Grandy, A.S. and Robertson G.P. 2006. Aggregation and organic matter protection following tillage of a previously uncultivated soil. Soil Sci. Soc. Am. J. 70(4): 1398-1406.

Heimann, M. and Reichstein M. 2008. Terrestrial ecosystem carbon dynamics and climate feedbacks. Nature 451:289292.

IPCC. 1996. Climate change 1995; the science of climate change. Contribution of WGI to the Second Assessment Report of the Intergovernmental Panel on Climate Change. Cambridge University Press, Cambridge. 572 p.
IPCC. 2007. Climate Change: Mitigation of Climate Change. Working Group III. Cambridge, UK: Cambridge University Press.

Lal, R. 2008. Carbon sequestration. Philos. Trans. R. Soc. B Biol. Sci. 363(1492): 815-830.

Luo, Y. 2007. Terrestrial carbon-cycle feedback to climate warming. Annual Review of Ecology, Evolution And Systematics 38:683-712.

Machmuller, M.B., Kramer, M.G., Cyle, T.K., Hill, N., Hancock, D. and Thompson, A. 2015. Emerging land use practices rapidly increase soil organic matter. Nat. Commun. 6: 6995.

McDaniel, M.D., Tiemann, L.K. and Grandy A.S. 2014. Does agricultural crop diversity enhance soil microbial biomass and organic matter dynamics? A metaanalysis. Ecol. Appl. 24(3): 560-570.

Milesi, C., Running, S.W., Elvidge, C.D., Dietz, J.B., Tuttle, B.T. and Nemani, R.R. 2005. Mapping and modeling the biogeochemical cycling of turf grasses in the US. Environmental Management 36(3):426-438.

Morgan, Jack A., Follett, Ronald F., Hartwell, Leon Jr., Allen, Grosso, Stephen Del, Derner, Justin D., Dijkstra, Feike, Franzluebbers, Alan, Fry, Robert, Paustian, Keith and Schoeneberger, Michele M. 2010. Carbon sequestration in agricultural lands of the United States. Journal of soil and water conservation; 65(1): 6-13.

Nair, P.K.R. and Nair V.D. 2003. Carbon storage in North US agroforestry systems. The Potential of US Forest Soils to Sequester Carbon and Mitigate the Greenhouse Effect, ed. J. Kimble et al., 333-346. Boca Raton, FL: CRC Press.

Parr, M., Grossman, J.M., Reberg-Horton, S.C., Brinton, C. and Crozier, C. 2014. RollerCrimper Termination for Legume Cover Crops in North Carolina: Impacts on Nutrient Availability to a Succeeding Corn Crop. Commun. Soil Sci. Plant 
Anal. 45(8): 1106-1119.

Powlson, D.S., Stirling, C.M., Jat, M.L., Gerard, B.G., Palm, C.A., Sanchez, P.A. and Cassman, K.G. 2014. Limited potential of no-till agriculture for climate change mitigation. Nat. Clim. Change 4(8): 678-683.

Robertson, G.P., Dale, V.H., Doering, O.C., Hamburg, S.P., Melillo, J.M., Wander, M.M., Parton, W.J., Pouyat, R., Adler, P.R., Barney, J., Cruse, R.M., Duke, C.S., Fearnside, P.M., Follett, R.F., Gibbs, H.K., Goldemberg, J., Mladenoff, D., Ojima, D., Palmer, M.W., A. Wallace, Sharpley, L., Weathers, K.C., Wiens, J.A. and Wilhelm, W.W. 2008. Sustainable Biofuels Redux. Science. 322: 49-50.

Rodale Institute. 2015. Organic No-till | Rodale Institute. Available at http://rodaleinstitute.org/ourwork/organic-no-till/ (verified 16 September 2015).

Runion, G.B., Torbert, H.A., Prior, S.A. and Rogers, H.H. 2009. Effects of elevated atmospheric carbon dioxide on soil carbon in terrestrial ecosystems of the southeastern US. In Soil Carbon Sequestration and the Greenhouse Effect, SSSA Special Publication 57, 2nd ed., ed. R. Lal and R.F. Follett, 233262, Madison, WI: Soil Science Society of America.

Schmidt, M.W.I., Torn, M.S., Abiven, S., Dittmar, T., Guggenberger, G., Janssens,
I.A., Kleber, M., Kogel-Knabner, I., Lehmann, J., Manning, D.A.C., Nannipieri, P., Rasse, D.P., Weiner, S. and Trumbore, S.E. 2011. Persistence of soil organic matter as an ecosystem property. Nat. Lond. 478(7367): 49-56.

Su, J., Hu, C., Yan, X., Jin, Y., Chen, Z., Guan, Q., Wang, Y., Zhong, D., Jansson, C., Wang, F., Schnürer, A. and Sun, C. 2015. Expression of barley SUSIBA2 transcription factor yields highstarch low-methane rice. Nature. 523(7562): 602-606.

Surya Prabha, A.C., Senthivelu, M. and Paramasivam, A. 2012. Carbon Sequestration Potential in Different Land Uses: A Review. International Journal of Environmental Research and Development; 15(9): 727-736.

Tiemann, L.K., Grandy, A.S., Atkinson, E.E., Marin-Spiotta, E. and McDaniel, M.D. 2015. Crop rotational diversity enhances belowground communities and functions in an agroecosystem. Ecol. Lett. 18(8): 761-771.

World Bank. 2015a. Agricultural nitrous oxide emissions (\% of total). Available at http://data.worldbank.org/indicator/EN. ATM.NOXE.AG.ZS/countries/1W?displ ay=grap $h$ (verified 1 October 2015).

World Bank. 2015b. Agricultural methane emissions (\% of total). Available at http://data.worldbank.org/indicator/EN. ATM.METH.AG.ZS/countries/1W?displ ay=grap $\mathrm{h}$ (verified 1 October 2015).

\section{How to cite this article:}

Mukesh Gupta, D. K. Vani and Sourav Gupta. 2020. Carbon Sequestration in Soils for Different Land Use Systems: A Review. Int.J.Curr.Microbiol.App.Sci. 9(11): 3796-3817. doi: https://doi.org/10.20546/ijcmas.2020.911.456 